\title{
Interactions between environmental quality and economic development in Shanghai, China
}

\author{
X. Ni ${ }^{1}$, J. Lu ${ }^{2} *$ L. Lan ${ }^{1}$, F.Q. Gao ${ }^{1}$, C.L. Pan $^{1}$ \\ ${ }^{1}$ Shanghai Water Information Center, Jiangsu Road 358, Shanghai 200050, PR CHINA \\ ${ }^{2 *}$ School of Civil and Environmental Engineering, Georgia Institute of Technology,Atlanta, Georgia 30332, USA \\ "Corresponding Author: e-mail: lujian.leonard@gmail.com (Jian Lu)
}

\begin{abstract}
This paper investigates the relationship between environmental quality and economic growth in Shanghai based on the environmental Kuznets curve hypothesis (EKC), using the panel data over 1989-2004. Regarded as the largest city and economic center in China, Shanghai has profoundly changed the local environment with the highest income level in this country. Ambient air quality, surface water quality and near-shore water quality from Shanghai are used as environmental indicators and per capita GDP is used as the economic indicator. We found four types of economy-environment relationships in the studied period in Shanghai. The results also show that surface water indicator supports EKC better than the ambient air and near-shore water indicator.
\end{abstract}

Keywords: Environmental quality, Economic growth, Environmental Kuznets curve

\section{Introduction}

China is the world's most populous country, and also one of the largest growing economies in the world. Together with its economic impact, Chinese environmental impact on the global environment is rapidly increasing, with ramifications that extend beyond its borders (Liu and Diamond, 2005). This paper therefore undertakes a preliminary investigation between economic growth and environmental quality in Shanghai, the most important economic center in China.

Shanghai is one of the largest cities in China with a population of 18.16 million people living in the year 2007 (Shanghai Statistical Bureau, 2007). It is located at the junction of the Yangtze River and the East China Sea, which has an area of approximately $6,400 \mathrm{~km}^{2}$ (Figure 1). As the Chinese largest special economic zone, Shanghai has developed into an international economic, financial, and trade center since 1978 (Hong, 2003; Ye et al., 2006). It has also been chosen as the city of 2010 World Expo. In terms of environmental protection, the Shanghai Municipal Government took the action of Three-Year Environmental Protection Plan since 2001, successfully following the concept of developing the economy without damaging the environment, a so-called "Double Win" strategy. Thus the city raised our particular interest for exploring the relationship between development and environment.

The interaction between economic growth and environmental quality has long been a subject of constant concern and research (Bartz and Kelly, 2008; Eriksson and Persson, 2003; Galeotti, 2007; Lehtonen, 2007; Lei et al., 2006). For researchers in the past, analysis methodology the most frequently adopted is the Environmental Kuznets Curve (EKC) hypothesis, which holds points that economic development and environmental degradation can be expressed by an inverted-U curve (Bagliani et al., 2008; Kuznets, 1955; Verbeke and De Clercq, 2006). It assumes that environmental degradation increases when per capita income is at a relatively low level, but that it will start to decline when per capita income reaches one certain point (turning point).

The discovery triggered substantial research efforts in this area, theoretical as well as empirical. The theoretical literatures have mainly focused on the assumptions required with respect to technology/preferences and pollutants for an EKC relationship (Andreoni and Levinson, 2001; Dinda, 2005; Lawn, 2006; Lopez, 1994). In general, the empirical model is a reduced form type, specifying pollutants as a non-linear function of income or a number of country specific characteristics such as population density, trade intensity and openness to trade (Cole et al., 1997; Jia et al., 2006; Kumar and Aggarwal, 2003). However, the data used in 
two literatures were basically the cross sectional data rather than the panel data over relatively short time and the pollutant indicators were the simple atmosphere emissions (e.g., $\mathrm{CO}_{2}, \mathrm{SO}_{2}$, etc.) (Huang et al., 2008; Keith et al., 2006).

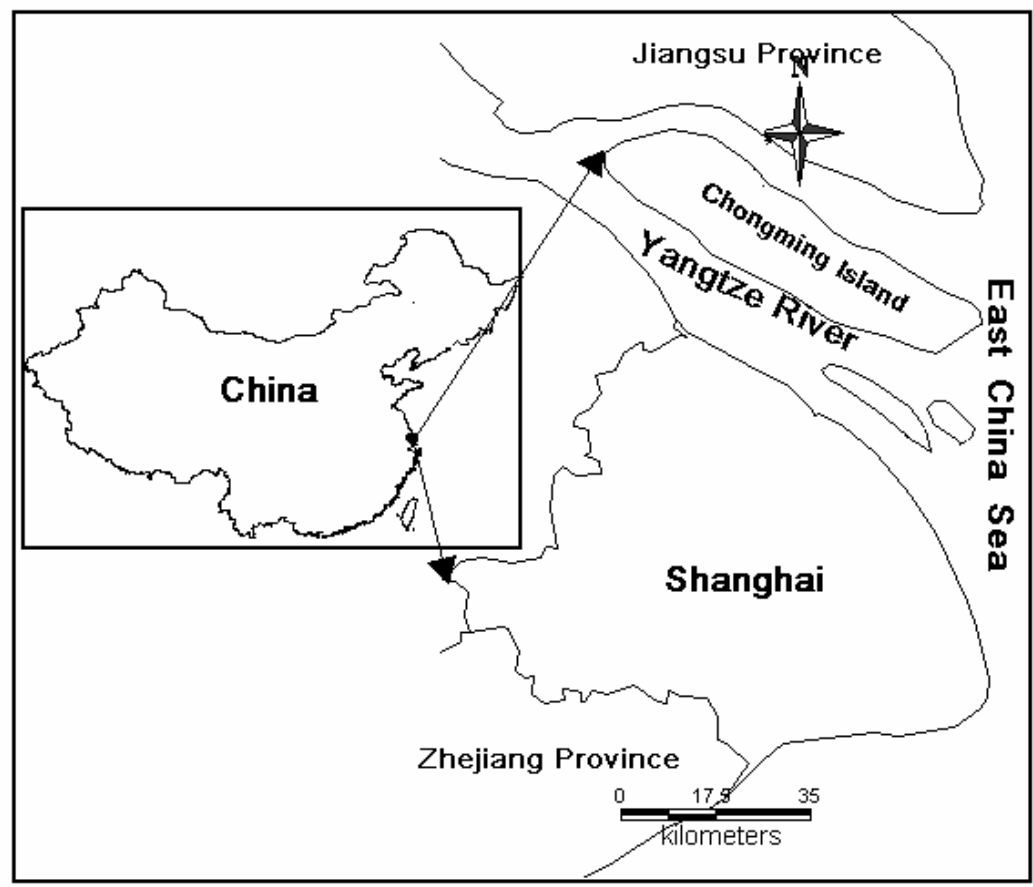

Figure 1. The Location of Shanghai

A standard EKC model (Stern, 2004) was adopted in order to examine the development-environment relationship in this paper. Eleven pollutants are used, which have been monitored by Chinese Environmental Monitoring System. These pollutants are supposed to indicate the quality of ambient air, river water environment and near-shore water environment in Shanghai from 19892004. The Nemerow index (Nemerow, 1985) is introduced as an integrated indicator for overall environmental quality. We hypothesize that an EKC shaped relationship between development and environment is possible in Shanghai.

The structure of this paper is as follows. We analyze the trends of gross domestic product (GDP) and environmental quality in Shanghai in Section 2. In Section 3, we provide the standard EKC model framework and apply the model, using per capita income as independent variable and the concentrations of different kinds of pollutants or the Nemerow index as dependent variables. Result analysis and discussion are presented in Section 4. This paper obtains some concluding remarks in Section 5.

\section{Data analysis and data source}

2.1 Data source: The data used in this paper are about the field of economy and environment in Shanghai. The economic and ambient air quality data were obtained from Shanghai Statistics Annual (1989-2004). The Surface water quality data were collected from unpublished data provided by the Shanghai Environmental Monitoring Station. The data source of near-shore water quality were from Shanghai Seawater Environmental Report of each year.

2.2 Economic development in Shanghai: Shanghai is the economic center in China. Together with its surrounding smaller cities, the Yangtze River Delta is becoming the largest economic development region in Asian (Dougless 2000). Shanghai has maintained a high economic growth rate, with the growth rate of Gross Domestic Product (GDP) consistently above 10\% since 1990. By the end of 2004, the GDP in Shanghai reached 7450.27 billion RMB. The per capita GDP in the city was over 55,000 RMB, which was about 5 times as high as the national-wide average level (Figure 2).

According to national statistics from1989 to 2004, the major contributing sectors to GDP growth in Shenzhen are the secondary and the tertiary sectors of industry accounting for respectively $54 \%$ and $45 \%$ of the city's total GDP. The primary sector of industry only accounts for $1 \%$ of the total GDP. The pillar industries of the city are information technology, finance service, automobile production, and real estate. 

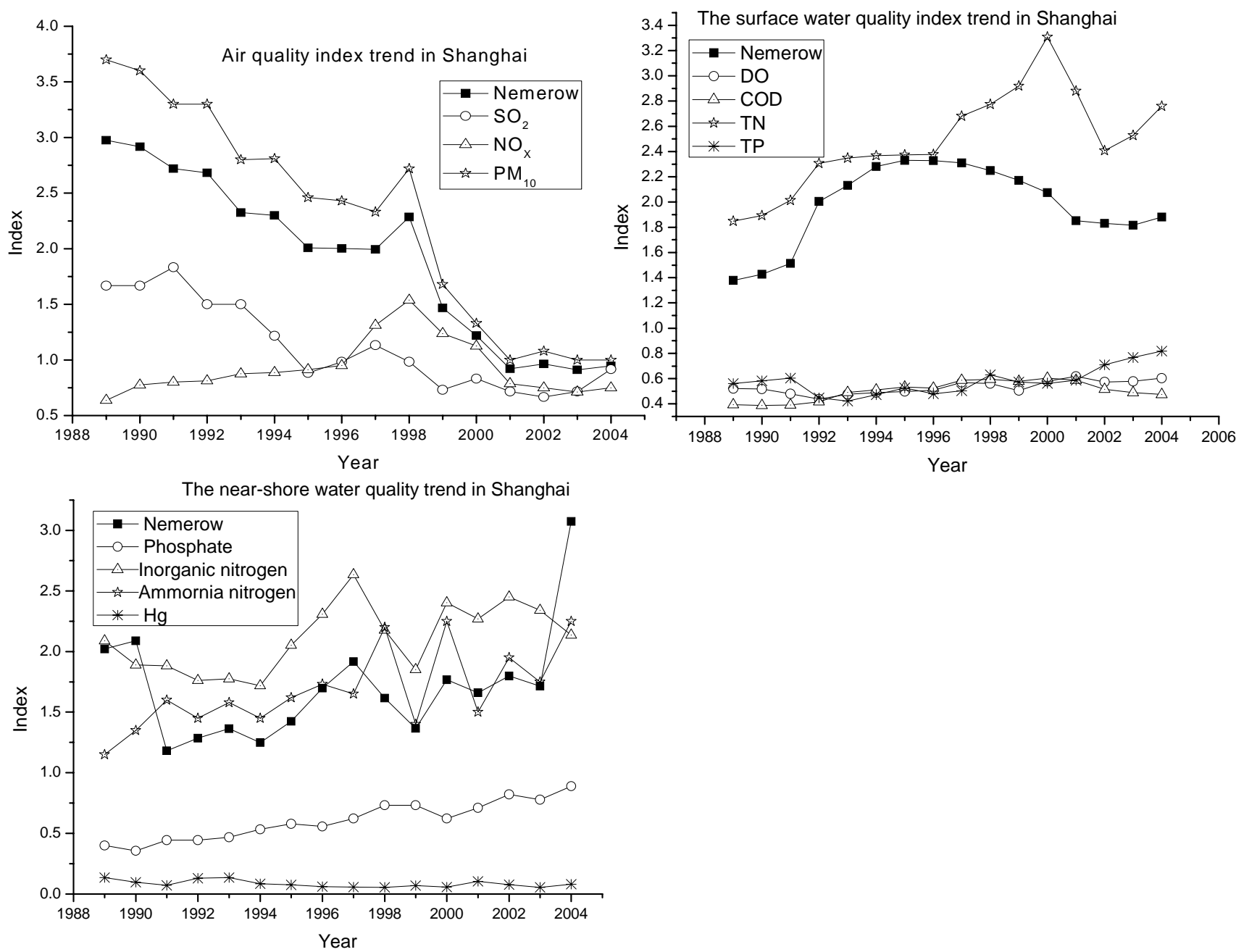

Figure 2 Environmental quality trends over 1989-2004 in Shanghai

2.3 The environmental quality trends in Shanghai: To evaluate the overall environmental quality, we used the Nemerow index, which reflected both maximum and average values of pollutants' concentrations relative to their objective levels:

$$
I=\sqrt{\frac{\operatorname{MaxI}_{\mathrm{i}}^{2}+\operatorname{AvgI}_{\mathrm{i}}^{2}}{2}}
$$

where $I_{i}$ is the pollution index relating the observed concentration $C_{i}$ of pollutant $i$ with its objective concentration $S_{i}$, $\mathrm{I}_{\mathrm{i}}=\mathrm{C}_{\mathrm{i}} / \mathrm{S}_{\mathrm{i}}$; $\operatorname{MaxI}_{\mathrm{i}}$ is the maximum value of all the indices $\mathrm{I}_{\mathrm{i}} ; \operatorname{AvgI}_{\mathrm{i}}$ is the average of all indices. If $\mathrm{I}>1$, the overall environmental quality does not comply with objectives; whereas if $\mathrm{I}<1$, the quality is better than the set objective.

(1) Ambient air quality: Three major air pollutants were monitored by Environmental Monitor Center in Shanghai: $\mathrm{SO}_{2}, \mathrm{NO}_{\mathrm{x}}$, and $\mathrm{PM}_{10}$. The air monitor network comprised 19 sampling points distributed around the city. Data were obtained through an automatic monitoring system. The values used in this paper are annual daily average values.

From 1989 to 2004, the overall air quality in Shanghai did not comply with the set municipality objective (the second standard for national ambient air quality). For the Nemerow index including $\mathrm{SO}_{2}, \mathrm{NO}_{\mathrm{x}}$, and $\mathrm{PM}_{10}$ maintains a level higher than the critical value $\mathrm{I}=1$ (Figure 2). However the air Nemerow index has been declining in the past 16 years, indicating the air quality is being improved in Shanghai. Among the three pollutants, only the quality of $\mathrm{NO}_{\mathrm{x}}$ is better than the objective without showing significant change. The other two have the same characteristic with Nemerow index. In terms of the contributions to the air pollution, the $\mathrm{NO}_{\mathrm{x}}$ is increasing while $\mathrm{PM}_{10}$ is declining (Figure 3). 

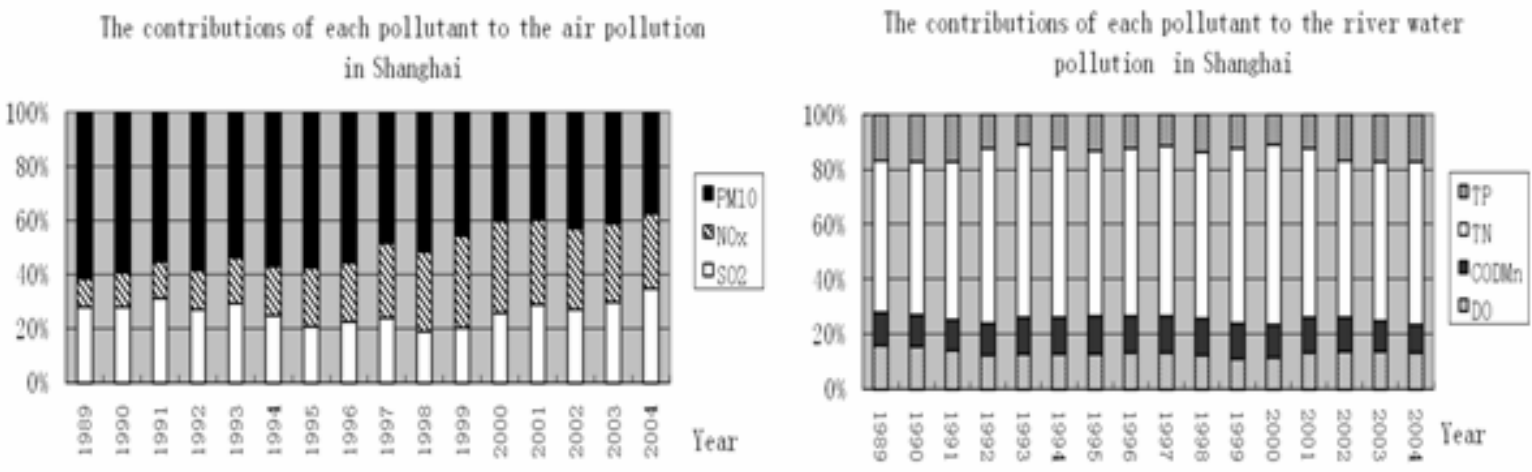

The contributions of each pollutant to the near-shore
water pollution in Shanghai

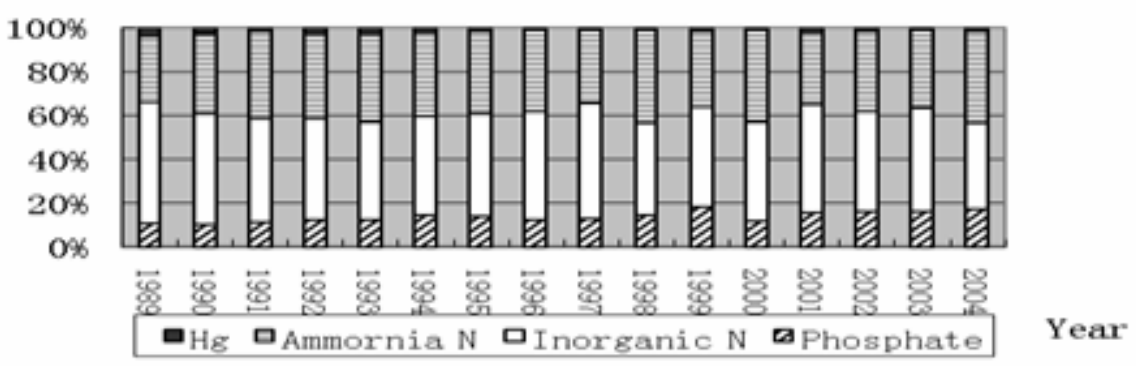

Figure 3 The contributions of each pollutant to its total pollution index in Shanghai over 1989-2004

(2) Surface water quality: In Shanghai, the Huangpu River is considered to be representative of surface water quality, which bisects the city. Therefore, it is studied here. The indicators monitored are dissolved oxygen (DO), chemical oxygen demand $\left(\mathrm{COD}_{\mathrm{Mn}}\right)$, total phosphate $(\mathrm{TP})$, and total nitrogen $(\mathrm{TN})$. The data is the annual mean value of eleven monitor site in Huangpu River. The water quality objective chosen is the fourth class of national standard for surface water, as set by State Environmental Protection Agency in China.

During the past decades, the surface water quality in Huangpu River firstly deteriorated and then started to improve (Figure 2). The nemerow index indicated that the quality on the whole was a little worse than the set objective. As a matter of fact, DO, $\mathrm{COD}_{\mathrm{Mn}}$, and TP all complied with the objective well. The dominant water pollutant is TN, its index was three times more than the critical value ( $\mathrm{I}=1$ ) in 2001. Meanwhile, it is always the largest contributions to the surface water pollution, which accounts about a level of $50 \%$ from 1989 to 2004 . Among all the pollutants, the index of $\mathrm{COD}_{\mathrm{Mn}}$ is the best, maintaining a low level and accounting the least proportion contributed to the overall surface water pollution (Figure 3).

(3) The near-shore water quality: Shanghai is located at the west of the East Sea; a lot of pollutants produced by the industry are ultimately discharged to the sea. The water environmental quality near the East Sea is sensitive for the local people. Sampling sites are mainly placed at the mouth of Yangtze River. The water samples were collected twice each month in the months of January, May, August, and November. The set objective is the third level national seawater standard of China (GB 3097-1997). The indicators monitored in the near-shore waters are phosphate, ammonia nitrogen, inorganic nitrogen (IN) and Hg.

The Nemerow shows that the near-shore water quality did not comply with the set objective (Figure 2). It has no significant changing trend in past decades. Except $\mathrm{Hg}$, the other three pollutants all show the increasing trends. In relation to the contributions of each pollutant to the near-shore water pollution, they are almost constant. The main pollutant is inorganic nitrogen and ammonia nitrogen (Figure 3).

\section{Methodology}

A standard Environmental Kuznets Curve (EKC) is expressed as a quadratic function of the income. We applied this model to describe the link between economic growth and environmental pollution in Shanghai. 


$$
\mathrm{I}_{\mathrm{t}}=\beta_{0}+\beta_{1}\left(\frac{\mathrm{GDP}}{\mathrm{P}}\right)_{\mathrm{t}}+\beta_{2}\left[\left(\frac{\mathrm{GDP}}{\mathrm{P}}\right)_{\mathrm{t}}\right]^{2}+\mathrm{e}_{t}
$$

where $I_{t}$ is an environmental pollution indicator in year $\mathrm{t} ; \mathrm{P}$ is the population size; $\mathrm{e}_{\mathrm{t}}$ is the error term; $\beta_{0}, \beta_{1}$, and $\beta_{2}$ are the estimated parameters. If the coefficient $\beta_{1}$ is negative and $\beta_{2}$ is positive, Eq. (2) corresponds to the standard EKC model, and the turning point is $-\beta_{1} / 2 \beta_{2}$.

In this paper, we used Nemerow and major pollutants index identified in previous section as the environmental dependent variable $I_{t}$, and we chosen the real per capita GDP, which had been adjusted in consideration of inflation, as economic independent variable $\left(\frac{\mathrm{GDP}}{\mathrm{P}}\right)_{\mathrm{t}}$.

\section{Results}

4.1 Analysis on ambient air quality: For the Nemerow index, the plot has a significant downward curve trend. It shows that the overall air quality was improved with the economic development in the studied period in Shanghai. For the other three variables, $\mathrm{SO}_{2}$ has one U-shaped curve, $\mathrm{PM}_{10}$ is the same as the Nemerow index, and only $\mathrm{NO}_{\mathrm{x}}$ shows an inverted U-shaped relationship clearly (Figure 4). Meanwhile, the coefficients of the models for $\mathrm{NO}_{\mathrm{x}}$ in Eq. (2) also support the EKC. The turning point is 28,470 RMB, which is much lower than the world mean value (5,000-8,000 USD) (Pfaff et al., 2004). This research used the t-statistic to examine the effect of the parenthesis estimation. The results for the statistical analysis are shown in Table 1.
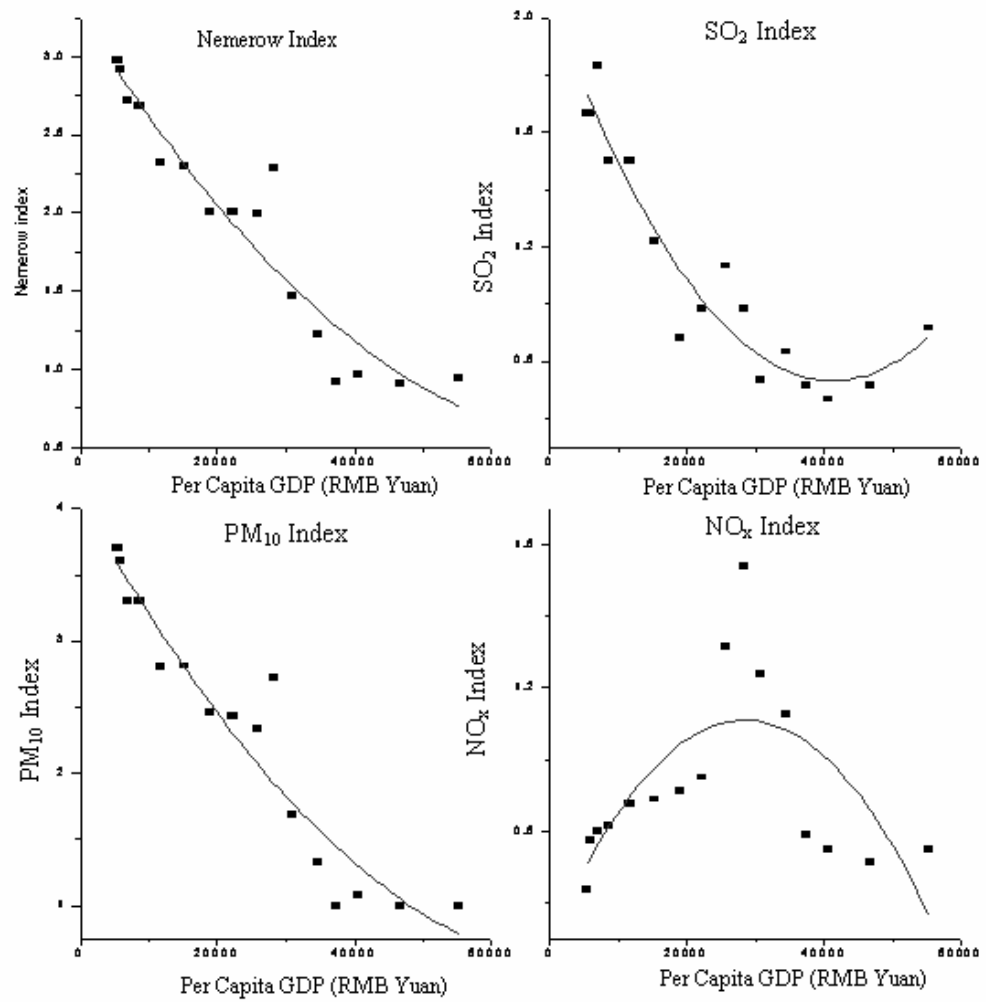

Figure 4 The relationship between per capita GDP and air quality in Shanghai

Table 1. The fitting result of the EKC model on ambient air quality in Shanghai

\begin{tabular}{|c|c|c|c|c|c|c|c|c|}
\hline $\begin{array}{c}\text { Dependent } \\
\text { variable }\end{array}$ & $\mathrm{R}^{2}$ & $\begin{array}{c}\text { Adjusted } \\
\mathrm{R}^{2}\end{array}$ & $\mathrm{~F}$ & $\mathrm{p}(\mathrm{F})$ & $\beta_{0}$ & $\beta_{1}$ & $\beta_{2}$ & $\begin{array}{c}\text { Turing } \\
\text { point }\end{array}$ \\
\hline Nemerow & 0.909 & 0.895 & 65.142 & 0.000 & $3.277^{\#}$ & $-7.052 \mathrm{E}-5^{\#}$ & $4.522 \mathrm{E}-10^{\#}$ & \\
\hline $\mathrm{SO}_{2}$ & 0.918 & 0.905 & 73.063 & 0.000 & $2.060^{\#}$ & $-6.440 \mathrm{E}-5^{\#}$ & $7.804 \mathrm{E}-10^{\#}$ & \\
\hline $\mathrm{NO}_{\mathrm{X}}$ & 0.479 & 0.399 & 5.979 & 0.014 & $0.496^{\#}$ & $4.301 \mathrm{E}-5^{\# \#}$ & $-7.550 \mathrm{E}-10^{\# \# \#}$ & 28470 \\
\hline $\mathrm{PM}_{10}$ & 0.916 & 0.903 & 71.518 & 0.000 & $4.077^{\#}$ & $-9.331 \mathrm{E}-5^{\#}$ & $6.093 \mathrm{E}-10^{\#}$ & \\
\hline
\end{tabular}

Statistics for t-student in parentheses. ${ }^{\# \#} \mathrm{p}<0.001,{ }^{\# \#} \mathrm{p}<0.01,{ }^{\#} \mathrm{p}<0.05$. 
4.2 Analysis on surface water quality: As shown in Figure 5, the Nemerow index of surface water behaves the EKC characteristic obviously. It also shows that the surface water pollution has reached its top level at the turning point of 30,118 RMB. The inverted U-shaped relationship can be also seen in the pollutants of TN and $\mathrm{COD}_{\mathrm{Mn}}$. The overall patterns for DO and TP are different from those mentioned above. For DO in Shanghai, there is a significant upward trend. Though the coefficients of DO in Table 2 verify the existence of EKC, the model has no significant curvature yet; therefore the support of EKC remains ambiguous. For total phosphate (TP), a possible U-shaped relationship or an opposite EKC curve is observed (Figure 5).
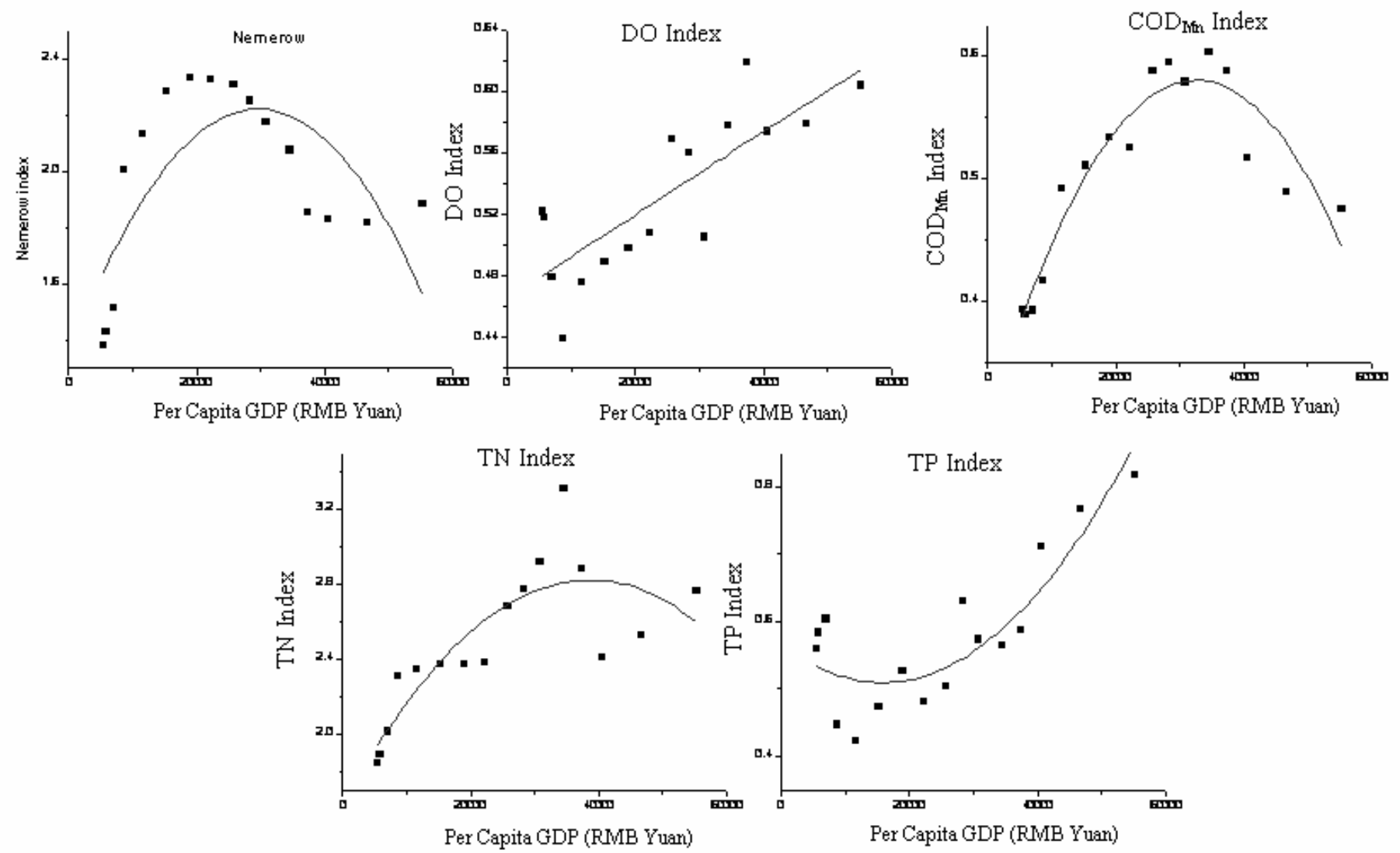

Figure 5 The relationship between per capita GDP and surface water quality in Shanghai

Table 2. The fitting result of the EKC model on surface water quality in Shanghai

\begin{tabular}{|c|c|c|c|c|c|c|c|c|}
\hline $\begin{array}{c}\text { Dependent } \\
\text { variable }\end{array}$ & $\mathrm{R}^{2}$ & adjust $\mathrm{R}^{2}$ & $\mathrm{~F}$ & $\mathrm{p}(\mathrm{F})$ & $\beta_{0}$ & $\beta_{1}$ & $\beta_{2}$ & $\begin{array}{c}\text { Turing } \\
\text { point }\end{array}$ \\
\hline Nemerow & 0.532 & 0.462 & 7.397 & 0.007 & 1.347 & $5.898 \mathrm{E}-5^{\# \#}$ & $-9.965 \mathrm{E}-10^{\# \#}$ & 30118 \\
\hline $\mathrm{DO}$ & 0.656 & 0.603 & 12.429 & 0.001 & 0.464 & $2.780 \mathrm{E}-6$ & $-1.1627 \mathrm{E}-12^{\#}$ & 119621 \\
\hline $\mathrm{COD}_{\mathrm{Mn}}$ & 0.905 & 0.890 & 62.251 & 0.000 & 0.301 & $1.7087 \mathrm{E}-5^{\#}$ & $-2.624 \mathrm{E}-10^{\#}$ & 32393 \\
\hline $\mathrm{TN}$ & 0.708 & 0.663 & 15.785 & 0.000 & 1.624 & $6.212 \mathrm{E}-5^{\#}$ & $-8.063 \mathrm{E}-10^{\#}$ & 38523 \\
\hline $\mathrm{TP}$ & 0.766 & 0.730 & 21.331 & 0.000 & 0.565 & $-7.174 \mathrm{E}-6$ & $2.273 \mathrm{E}-10^{\#}$ & \\
\hline
\end{tabular}

Statistics for t-student in parentheses. ${ }^{\# \#} \mathrm{p}<0.01,{ }^{\#} \mathrm{p}<0.05$.

4.3 Analysis on near-shore water quality: For the Nemerow index and $\mathrm{Hg}$, the plots show U-shaped relationships in studied period. On the contrary, for phosphate, inorganic nitrogen and ammonia nitrogen, they all show inverted U-shaped relationships (Figure 6). However, none of these curves' trend is obvious. The regression fitting is not as good as that of ambient quality and surface water quality. Except phosphate, the value of $\mathrm{R}^{2}$ and adjusted $\mathrm{R}^{2}$ are all less than 0.52 . The model parenthesis estimation of nearshore water quality is shown in Table 3. 

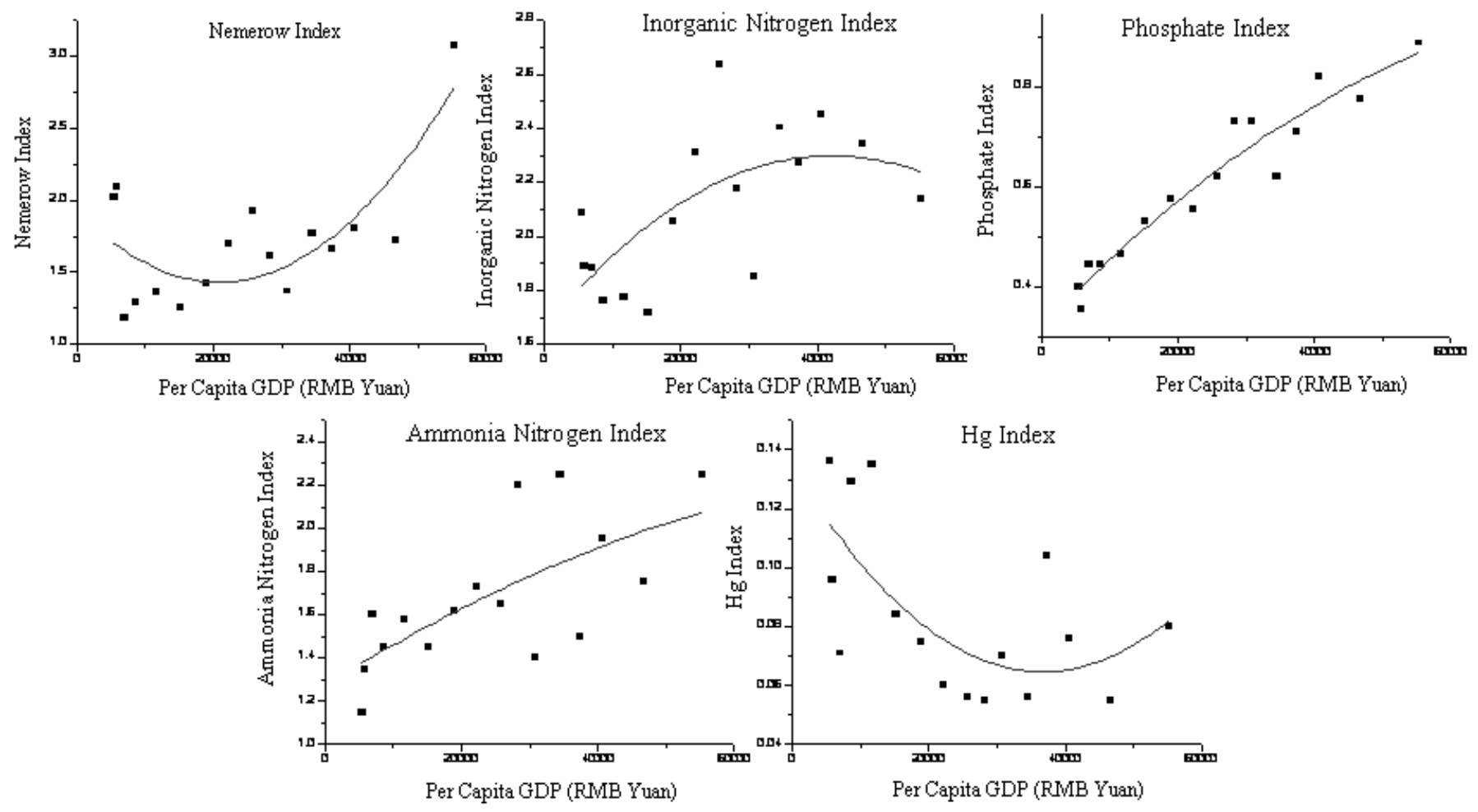

Figure 6 The relationship between per capita GDP and near-shore water quality in Shanghai

Table 3. The fitting result of the EKC model on near-shore water air quality in Shanghai

\begin{tabular}{|c|c|c|c|c|c|c|c|c|}
\hline $\begin{array}{c}\text { Dependent } \\
\text { variable }\end{array}$ & $\mathrm{R}^{2}$ & adjust $\mathrm{R}^{2}$ & $\mathrm{~F}$ & $\mathrm{p}(\mathrm{F})$ & $\beta_{0}$ & $\beta_{1}$ & $\beta_{2}$ & $\begin{array}{c}\text { Turing } \\
\text { point }\end{array}$ \\
\hline Nemerow & 0.578 & 0.514 & 8.933 & 0.003 & 1.923 & $-4.736 \mathrm{E}-5^{\# \#}$ & $1.137 \mathrm{E}-9^{\# \#}$ & \\
\hline phosphate & 0.927 & 0.916 & 82.819 & 0.000 & 0.320 & $1.411 \mathrm{E}-5^{\#}$ & $-7.601 \mathrm{E}-11^{\#}$ & 92828 \\
\hline $\begin{array}{c}\text { Inorganic } \\
\text { nitrogen }\end{array}$ & 0.427 & 0.338 & 4.846 & 0.026 & 1.659 & $3.041 \mathrm{E}-5^{\# \#}$ & $-3.621 \mathrm{E}-10^{\# \#}$ & 42002 \\
\hline $\begin{array}{c}\text { Ammonia } \\
\text { nitrogen }\end{array}$ & 0.466 & 0.384 & 5.690 & 0.016 & 1.274 & $1.947 \mathrm{E}-5$ & $-9.009 \mathrm{E}-11^{\# \#}$ & 108058 \\
\hline Hg & 0.429 & 0.341 & 4.883 & 0.026 & 0.134 & $-3.774 \mathrm{E}-6^{\# \#}$ & $5.134 \mathrm{E}-11^{\# \#}$ & \\
\hline
\end{tabular}

Statistics for t-student in parentheses. ${ }^{\# \#} \mathrm{p}<0.001,{ }^{\#} \mathrm{p}<0.01,{ }^{\#} \mathrm{p}<0.05$.

\section{Discussion}

The environment-development relationship was studied through the EKC theory based on the panel data in Shanghai. In comparison to most other studies, the study area is just one city. But on the other hand, our environmental data are comprehensive and of good quality. Our study shows four types of environment-development relationships in Shanghai: classical EKC, upward pattern, downward pattern, and inverted EKC. For the upward and downward patterns, they do not necessarily disprove the EKC, only proving that EKC are not shown in the observed range of GDP. Thus it is important to realize that the time frame of observations have decisive effects, otherwise, either the decreasing or the rising leg of the curve may be missed.

What is the main reason that most of the surface water indicators display the EKC well, nevertheless, most of the air and nearshore water indicators seem to disprove the EKC in Shanghai? In the 1980s, a lot of production enterprises were settled down in the city, which polluted the Huangpu River. When the river water quality deteriorated in the middle of 1990s, more funds and technology were allocated to improve the surface water quality by the government. In addition, strict regulations on pollution enterprises ware enforced in order to decrease the pollutants discharged into the river. These provide not only an incentive for moving production to places where environmental regulation is less stringent but also some clean-up technology. Therefore, the surface water quality on the whole exhibits the EKC in the studied period in Shanghai. In fact, the downward and EKC pattern of the ambient air can also be explained by the government's environmental regulations and the citizens' environmental consciousness. 
As the results show, different indicators we used exhibit different curves trend for the environment-development relationship in Shanghai. Based on this, one region supporting the EKC has the relation to the independent variables of the model. For the variables supporting the EKC, the turning point has much difference. In this paper, the maximal turning point is 119,621 RMB, and the minimal turning point is just $28,470 \mathrm{RMB}$. Furthermore, as many counties and cities are already promoting pollution reduction project, a lot of factors that are beyond the control of the model are being created, such as innovative technology, trade, and policy. Further EKC research is needed in order to integrate and incorporate these additional factors.

\section{Conclusion}

This research observed that the economic development and environmental quality exhibit four kinds of curve trend in Shanghai, China: upward, downward, EKC, and inverted EKC. The surface water indicators mostly support the EKC, while the indicators of ambient air and near-shore water do not. The existence of EKC in river is mainly due to relocation of pollution and clean-up technology by the government and market interventions. For the indicators support the EKC, most of them have got through the turning point, and their environmental qualities are being improved with the economic development. In addition, the time frame and the indicators of observations we chose may have decisive effects when interpreting the environment-development relationships based on the EKC hypothesis. Our findings suggest a potential environmental policy option for cities and nations in varying stages of development. Nonetheless, the effect of economic growth on the environment is an important problem and is therefore deserving of continued research.

\section{References}

Andreoni, J., Levinson, A. 2001. The simple analytics of the environmental Kuznets curve .Journal of Public Economics, Vol. 80, No. 2, pp. 269-286.

Bagliani, M., Bravo, G. and Dalmazzone, S. 2008. A consumption-based approach to environmental Kuznets curves using the ecological footprint indicator. Ecological Economics, Vol. 65, No. 3, pp. 650-661.

Bartz, S. and Kelly, D.L. 2008. Economic growth and the environment: Theory and facts. Resource and Energy Economics, Vol. 30, No. 2, pp. 115-149.

Cole, M.A., Rayner, A.J. and Bates, J.M. 1997. The environmental Kuznets curve: An empirical analysis. Environment and Development Economics, Vol. 2, No. 4, pp. 401-416.

Dasgupta, S., Laplante, B., Wang, H. and Wheeler, D. 2002. Confronting the environmental Kuznets curve. The Journal of Economic Perspectives, Vol. 16, pp. 147-168.

Dinda, S. 2005. A theoretical basis for the environmental Kuznets curve. Ecological Economics, Vol. 53, No. 3, pp. 403-413.

Douglass, M. 2000. Mega-urban regions and world city formation: globalization, the economic crisis and urban policy issues in Pacific Asia. Urban Studies, Vol. 37, pp. 2315-2335.

Eriksson, C. and Persson, J. 2003. Economic growth, inequality, democratization, and the environment. Environmental and Resource Economics, Vol. 25, No. 1, pp. 1-16.

Galeotti, M. 2007. Economic growth and the quality of the environment: Taking stock. Environment, Development and Sustainability, Vol. 9, No. 4, pp. 427-454.

Hong, W. 2003. An assessment of the business environment for high-tech industrial development in Shanghai Environment and Planning. Government and Policy, Vol. 21, No. 1, pp. 107-137.

Huang, W.M., Lee, G.W.M. and Wu, C.C. 2008. GHG emissions, GDP growth and the Kyoto Protocol: A revisit of Environmental Kuznets Curve hypothesis. Energy Policy, Vol. 36, No. 1, pp. 239-247.

Jia, S., Yang, H., Zhang, S., Wang, L. and Xia, J. 2006. Industrial water use kuznets curve: Evidence from industrialized countries and implications for developing countries. Journal of Water Resources Planning and Management, Vol. 132, No. 3, pp. 183191.

Keith, D.W., Ha-Duong, M. and Stolaroff, J.K. 2006. Climate strategy with $\mathrm{CO}_{2}$ capture from the air. Climatic Change, Vol. 74, No. 1-3, pp. 17-45.

Kumar, P. and Aggarwal, S.C. 2003. Does an environmental Kuznets curve exist for changing land use? Empirical evidence from major states of India. International Journal of Sustainable Development, Vol. 6, No. 2, pp. 231-245.

Kuznets, S. 1955. Economic and income inequality. American Economy Review, Vol. 45, pp. 1-28.

Lawn, P. 2006. A theoretical investigation into the likely existence of the Environmental Kuznets Curve. International Journal of Green Economics, Vol. 1, No. 1-2, pp. 121-138.

Lehtonen, M. 2007. Environmental policy integration through OECD peer reviews: Integrating the economy with the environment or the environment with the economy? Environmental Politics, Vol. 16, No. 1, pp. 15-35.

Lei, K. P., Chen, F. P. and Wang, Z. S. 2006. The emergy synthesis and sustainability analysis of city's environment and economy. Acta Ecological Sinica, Vol. 26, No. 2, pp. 439-448.

Liu, J. and Diamond, J. 2005. China's environment in a globalizing world. Nature, Vol. 435, No. 7046, pp. 1179-1186. 
Lopez, R. 1994. The environment as a factor of production: the effects of economic growth and trade liberalization. Journal of Environmental Economics and Management, Vol. 27, No. 2, pp. 163-184.

Nemerow, N.L. 1985. Stream, Lake, Estuary, and Ocean Pollution. Van Nostrand Reinhold, New York.

Pfaff, A., Barelli, P. and Chaudhuri, S. 2004. Aid, economic growth and environmental sustainability: Rich-poor interactions and environmental choices in developing countries. International Journal of Global Environmental Issues, Vol. 4, No. 1-3, pp. 139159.

Shanghai Statistics Bureau, 2004. Shanghai Statistics Yearbook. Shanghai Statistics Bureau, China.

Stern, D.I. 2004. The Rise and Fall of the Environmental Kuznets Curve. World Development, Vol. 32, No. 8, pp. 419-1439.

Verbeke, T. and De Clercq, M. 2006. The EKC: Some really disturbing Monte Carlo evidence. Environmental Modeling and Software, Vol. 21, No. 10, pp. 1447-1454.

Ye, X.J., Zhou, Z.P., Lian, Z.W., Liu, H.M., Li, C.Z. and Liu, Y.M. 2006. Field study of a thermal environment and adaptive model in Shanghai. Indoor Air, Vol. 16, No. 4, pp. 320-326.

\section{Biographical notes}

X. Ni is a Ph.D candidate from Shanghai Jiao Tong University, and he is an engineer in Shanghai Water Information Center, Shanghai, China. His current area of research includes Environmental Protection, Water Resources Management, Multi-criteria Decision-Making, and Non-traditional Optimization and Simulation. He has published several papers in referred international and national journals. He is currently dealing with a few projects sponsored by government of China.

J. Lu is currently a research engineer studying the transport and fate of hazardous pollutants in engineered bioremediation and natural systems at Georgia Institute of Technology. He graduated from Shanghai Jiao Tong University in 2008 and received his $\mathrm{Ph}$. D degree in environmental engineering. He focuses his research interests on the biodegradation or biotransformation behaviors of hazardous pollutants and related treatment techniques for water, air \& soil pollution. Research on environment sustainability and bio-energy technology such as microbial fuel cell technique is also included.

L. Lan is an engineer in Shanghai Water Information Center, Shanghai, China. She has more than eight years experience of water resources planning and protection. Her research interests include Water Resources Protection and Ocean Environmental Protection.

F.Q. Gao received Ph.D. from East China Normal University, China in 2005. Presently, she works in Shanghai Water Information Center. Her research interests include Geology Information System, Water Resources Protection and Environmental Planning. She has published more than ten papers in national journals and conferences.

C.L. Pan is an engineer in Shanghai Water Information Center, Shanghai, China. He received Master degree. in 2005. His research interests include Water Resources Planning, Computer System Restructuring, Computer System Optimization \& Control and Environmental Protection.

Received August 2010

Accepted September 2010

Final acceptance in revised form September 2010 